\title{
Does the Sophomore Slump Really Exist?
}

\section{Debra Wetcher-Hendricks ${ }^{1}$}

Various statisticians and sports analysts have addressed the role of regression to the mean in major league sports performances. This paper intensifies general findings on the topic, specifically, that of Schall and Smith (2000), to focus upon regression with respect to the widely-acknowledged sophomore slump. Results of the analysis yield two main findings. First, players' comparatively poor performances during their second seasons of play reflect uncharacteristically high first-season statistics, not low second-season statistics. Second, the degree of change in performance from the first to the second seasons clearly follows Campbell and Stanley's (1963) regression to the mean model. [Article copies available for a fee from The Transformative Studies Institute. E-mail address: journal@transformativestudies.org Website: http://www.transformativestudies.org (C2014 by The Transformative Studies Institute. All rights reserved.]

KEYWORDS: Regression to the Mean; Regression Artifacts; Sophomore Slump; Freshman Fluke.

\section{INTRODUCTION}

Sports players, analysts, and fans alike have long acknowledged the decline in performance that commonly occurs between the first and second years of players' careers. This phenomenon, nicknamed the

\footnotetext{
${ }^{1}$ Debra Wetcher-Hendricks, Ph.D., received her B.A. in journalism from Glassboro State College and her M.A. in Social Relations as well as her Ph.D. in Applied Social Research from Lehigh University. Currently, she is an Associate Professor of Sociology at Moravian College, in Bethlehem, PA. Her primary academic interests include social research and statistical methods, interpersonal communication, and mass communication. In addition to her published book, Analyzing Quantitative Data: An Introduction for Social Researchers, her articles describing analyses of statistical models and providing statistical analyses of sociological phenomena have appeared in peer-refereed journals and been presented at academic conferences. Various editions of Who's Who Among American Women, Who's Who in America, and Who's Who in the World have recognized her since 2008. Address correspondence to: Debra Wetcher-Hendricks, Moravian College, 1200 Main Street - Sociology Department, Bethlehem, PA 18018; e-mail: medwh02@moravian.edu.
} 